\title{
Review
}

\section{Chemical carcinogenesis studies in nonhuman primates}

\author{
By Shozo Takayama,${ }^{* 1, \dagger}$ Unnur P. Thorgeirsson ${ }^{* 2}$ and Richard H. AdAmson ${ }^{* 2}$
}

(Communicated by Takashi Sugimura, M.J.A.)

\begin{abstract}
This review covers chemical carcinogenesis studies in nonhuman primates performed by the National Cancer Institute, USA, to provide hitherto unavailable information on their susceptibility to compounds producing carcinogenic effects in rodents. From autopsy records of 401 breeders and untreated controls, incidences of spontaneous malignant tumors were found to be relatively low in cynomolgus (1.9\%) and rhesus monkeys (3.8\%), but higher in African green monkeys (8\%). Various chemical compounds, and in particular 6 antineoplastic agents, 13 food-related compounds including additives and contaminants, 1 pesticide, $5 \mathrm{~N}$-nitroso compounds, 3 heterocyclic amines, and 7 "classical" rodent carcinogens, were tested during the 34 years period, generally at doses 10 40 times the estimated human exposure. Results were inconclusive in many cases but unequivocal carcinogenicity was demonstrated for IQ, procarbazine, methylnitrosourea and diethylnitrosamine. Furthermore, negative findings for saccharine and cyclamate were in line with results in other species. Thus susceptibility to carcinogens is at least partly shared by nonhuman primates and rodents.
\end{abstract}

Keywords: chemical carcinogenesis, nonhuman primate, lifetime administration

\section{Introduction}

Malignant tumors arise due to accumulation of genetic and epigenetic changes caused by carcinogenic agents. Chemical carcinogenesis thus involves a series of complex events that result in the conversion of normal to malignant cells. A wide variety of chemicals have been shown to be capable of inducing malignant tumors, not only in rodents

*1 Guest Professor of Showa University School of Medicine, Tokyo, Japan.

*2 National Cancer Institute, MD, USA.

$\dagger$ Correspondence should be addressed: S. Takayama, Pharmaceutical Research Dept., Meiji Seika Kaisha, Ltd., 760 Morooka-cho, Kohoku-ku, Yokohama, Kanagawa 222-8567, Japan (e-mail: shozo_takayama0@meiji.co.jp).

Abbreviations: po, per os; ng, nasogastric; ip, intraperitoneal; iv, intravenous; DMSO, dimethyl sulfoxide; HPC, hydroxypropyl cellulose; MNU, N-methyl-N-nitrosourea; $\mathrm{AFB}_{1}$, aflatoxin $\mathrm{B}_{1}$; HCAs, heterocyclic amines; IQ, 2-amino-3-methylimidazo[4,5-f] quinoline; MeIQx, 8-dimethylimidazo-(4,5-f)quinoxaline; PhIP, 2-amino-1-methyl-6-phenylimidazo(4,5-b)pyridine; 2-AAF, 2-acetylaminofluorene; 3-MC, 3-methylcholanthrene; DMNA, dimethylnitrosoamine; DENA, diethylnitrosamine; DPNA, dipropylnitrosamine; MNNG, N-methyl$\mathrm{N}^{\prime}$-nitro-N-nitrosoguanidine; PIP, nitrosopiperidine; DDT, dichloro-diphenyl-trichloroethane (technical grade containing 70$80 \%$ 1,1'-(2,2,2-trichloro-ethylidene)bis(4-chlorobenzene)). but also in species belonging to other animal orders. ${ }^{1)-3)}$ Rodents are appropriate animal models for large-scale human carcinogenic risk assessment because of their relatively low cost, wealth of data regarding spontaneous tumor incidence, and the relative rapidity with which experimental results can be obtained.4),5) However, agents that are carcinogenic in humans are not always carcinogenic to rodents; for example, inorganic arsenic is a human carcinogen but is reported to have no such effect in rats. ${ }^{6)}$

Although it is impractical to use large animals, such as nonhuman primates, for large-scale carcinogenesis experiments, they represent valuable model systems for the following reasons: 1) the close phylogenic relationship to humans, and greater similarities with regard to anatomy, physiology, biochemistry and organ systems, as compared to rodents; 2) the relatively large organ size makes it possible to perform repeated diagnostic procedures, such as endoscopic examination, blood sample collection and biopsy, on the same animal over a long period; 3 ) the incidence of spontaneous tumors is low in comparison with rodents; and 4) the longevity of Old World monkeys, primarily 
found in Africa, makes carcinogenic exposure over long periods comparable to that in humans. However, obvious disadvantages are the high cost associated with the use of nonhuman primates in long-term carcinogenic studies and the time periods required.

This review summarizes data on spontaneous and chemically induced tumors in animals from studies begun in 1961 at the National Cancer Institute, NIH, USA and the National Cancer Research Institute, Japan. This is the largest and longest running chemical carcinogen testing program in nonhuman primates undertaken to date. The results of the studies have been detailed elsewhere. ${ }^{4), 5)}$ Furthermore, histological findings of normal tissue and neoplastic lesions in nonhuman primates were characterized by the authors. ${ }^{7,8)}$ Here, we focus on chemicals demonstrating carcinogenic activity preferentially in rodents, with comparisons to results with nonhuman primates.

\section{Materials and methods}

The monkey colony consisted of three species: Macaca fascicularis (cynomolgus monkey), Macaca mulatta (rhesus monkey), and Cercopithecus aethiops (African green monkey). All three species were bred at the facility since the commencement of the program in 1961, and served as the primary source of experimental animals. Purina High Protein Monkey Chow \#5045 was offered twice daily, and the animals also received a vitamin sandwich and a portion of apple daily.

The nonhuman primates were housed individually in stainless steel cages, which provided appropriate space as required by the Institutional Animal Welfare Act.

Since the initiation of this chemical carcinogenesis study, a total of 37 compounds have been evaluated, comprising 6 antineoplastic agents, 13 food additives, other components, and environmental contaminants, 7 "classical" rodent carcinogens, $5 \mathrm{~N}$-nitroso compounds, and 6 miscellaneous substances. In addition, 8 viruses and 6 vehicles for test compounds were tested. Results with 5 antineoplastic agents, 2 food additives, $3 \mathrm{HCAs}$, 2 food contaminants/pesticides, 2 N-nitroso compounds and some classical rodent carcinogens are reviewed here.

The test compounds were generally administered per os (po), in a vitamin mixture on a sandwich, by intraperitoneal (ip) injection, by intravenous (iv) injection or by nasogastric (ng) intubation. A total of 55 nonhuman primates were assigned to control groups receiving only vehicles for the different compounds, these being dimethyl sulfoxide (DMSO), hydroxypropyl cellulose (HPC), corn oil, olive oil, saline, distilled water, vitamin spread, syrup or apple sauce. Periodically, nonhuman primates were also assigned as controls with no treatment whatsoever. For most compounds, treatment was initiated at the time of weaning (approximately 6 months of age) or at 1 year of age.

The dose level was dependent upon the agent under evaluation. Cancer therapeutic agents were administered at doses likely to be encountered in clinical use, while other compounds were administered at 10-40 times the estimated human intake level, or at the maximum tolerated dose that did not cause severe organ toxicity or weight loss. Each nonhuman primate received a routine physical examination by a veterinarian every 6 months. Various hematological and biochemical tests were performed every 3 to 6 months, depending on the compound under evaluation. For early detection of liver tumors, measurement of serum $\alpha$-fetoprotein levels and abdominal laparoscopic examination of the liver were performed every 3 to 6 months, followed by histopathological examination of wedge or needle liver biopsy specimens.

A complete autopsy was performed on all nonhuman primates which died before the termination or were sacrificed at the end of the study. Data on tumor incidences were included from all animals surviving 6 months or longer after the first exposure to test compounds. Animals that died as a result of acute toxicity during the first 6 months of dosing were eliminated from the assessment. Such cases were experienced with some of the compounds examined earlier in the series of studies. The latent period for tumor development for all of the compounds investigated was more than 6 months.

\section{Results}

Spontaneous tumors. A total of 401 autopsy records for breeder and wild monkeys were reviewed to determine spontaneous tumor incidences (Table 1). The incidence of total malignant tumors was highest (8\%) in the African green monkeys, 3 of 
Table 1. Spontaneous tumor rates in the breeder and control animals

\begin{tabular}{|c|c|c|c|c|c|c|}
\hline Species & \multicolumn{2}{|c|}{ Total no. of monkeys } & \multicolumn{2}{|c|}{$\begin{array}{l}\text { No. of monkeys } \\
\text { with malignant tumors }\end{array}$} & \multicolumn{2}{|c|}{$\begin{array}{l}\text { No. of monkeys } \\
\text { with benign tumors }\end{array}$} \\
\hline \multirow{2}{*}{ Rhesus } & F 153 & \multirow{2}{*}{182} & 5 & \multirow{2}{*}{$7(3.8 \%)$} & 10 & \multirow{2}{*}{$11(6.0 \%)$} \\
\hline & M 29 & & 2 & & 1 & \\
\hline \multirow{2}{*}{ Cynomolgus } & F 128 & \multirow{2}{*}{157} & 1 & \multirow{2}{*}{$3(1.9 \%)$} & 2 & \multirow{2}{*}{$2(1.3 \%)$} \\
\hline & M 29 & & 2 & & 0 & \\
\hline \multirow{2}{*}{ African green } & F 47 & \multirow{2}{*}{62} & 1 & \multirow{2}{*}{$5(8.0 \%)$} & 0 & \multirow{2}{*}{$0(0 \%)$} \\
\hline & M 15 & & 4 & & 0 & \\
\hline Total & 401 & & 15 & & 13 & \\
\hline
\end{tabular}

Table 2. Summary of malignant tumor data for monkeys treated with antineoplastic and immunosupressive agents

\begin{tabular}{|c|c|c|c|c|c|}
\hline Agent & $\begin{array}{c}\text { No. of } \\
\text { monkeys }\end{array}$ & Route & $\begin{array}{l}\text { Daily dose } \\
\text { (mg/kg) }\end{array}$ & $\begin{array}{l}\text { No. of dead with } \\
\text { malignant tumor }\end{array}$ & Carcinogenicity \\
\hline $\begin{array}{l}\text { Doxorubicin } \\
\text { hydrochloride }\end{array}$ & 10 & iv & 0.2 & 0 & no \\
\hline $\begin{array}{l}\text { Doxorubicin } \\
\text { hydrochloride }\end{array}$ & 10 & iv & 0.4 & 1 & no \\
\hline $\begin{array}{l}\text { Doxorubicin } \\
\text { hydrochloride }\end{array}$ & 10 & iv & 1.0 & 1 & no \\
\hline Cyclophosphamide & 23 & po & 6.0 & 1 & $\begin{array}{c}\text { not } \\
\text { conclusive }\end{array}$ \\
\hline Melphalan & 20 & ng & 0.1 & 2 & $\begin{array}{c}\text { not } \\
\text { conclusive }\end{array}$ \\
\hline Procarbazine & 49 & $\mathrm{sc} / \mathrm{po}, \mathrm{ip} / \mathrm{po}$, or ip & 10 & 17 & yes \\
\hline $\mathrm{MNU}$ & $43^{\mathrm{b})}$ or $44^{\mathrm{c})}$ & po & 10 & 18 & yes \\
\hline
\end{tabular}

a) Number of animals surviving longer than 6 months after the first dose

${ }^{b)}$ See reference 13

c) See refernce 5

5 malignancies being non-Hodgkin's lymphomas, followed by rhesus and cynomolgus monkeys with incidences of $1.9 \%$ and $3.8 \%$, respectively. The three cynomolgus monkeys with tumors had adenocarcinomas of the kidney and colon, and a duct carcinoma of the breast. Seven rhesus monkeys developed malignant tumors, including two rhabdomyosarcomas in limbs. One of two poorly differentiated sarcomas in the peritoneal and perivaginal areas of unknown origin demonstrated metastasis to the lung. Two cases of squamous cell carcinomas in the tongue and bladder, respectively, and an adenocarcinoma of the bile duct were also observed. Spontaneous benign tumors were observed in 2 cynomolgus and 11 rhesus monkeys, 6 of the 11 benign tumors in the latter being uterine leiomyomas. $^{5)}$

Antineoplastic agents. A total of 166 monkeys were treated with one of 5 agents, of which 59 survived for 6 months or longer after the first dose. All 5 of the test agents in this category showed evidence of carcinogenicity, with tumor incidences of $6.7-40.9 \%$ (Table 2). ${ }^{4), 5)}$

Doxorubicin hydrochloride (Adriamycin). A total of 30 nonhuman primates (17 rhesus monkeys and 13 cynomolgus monkeys) received doxorubicin hydrochloride by the iv route. The first group of 10 animals received a dose of $0.2 \mathrm{mg} / \mathrm{kg}$ for 188 months, the second group received $0.4 \mathrm{mg} / \mathrm{kg}$ for 185 months, and the third group received $1.0 \mathrm{mg} / \mathrm{kg}$ for 114 months, then all were observed without further treatment. The doxorubicin hydrochloride was given once a month in all groups. One case of acute myeloblastic leukemia in rhesus monkeys after 32 months, and one case of low-grade fibrosarcoma at the injection site in the right leg in a cynomolgus monkey were observed after 134 months in the second group. ${ }^{4), 5)}$ 
Delayed cardiotoxicity is well documented in humans treated with doxorubicin hydrochloride. Similarly, dose-dependent cardiomyopathy was observed in all of the rhesus and cynomolgus monkeys in the $1.0 \mathrm{mg} / \mathrm{kg}$ group and 5 of the $0.4 \mathrm{mg} / \mathrm{kg}$ group. These animals developed myocardial degeneration and died as a result of congestive heart failure. ${ }^{9)}$ One of the authors (S.T.) performed histopathological examination of the myocardial degeneration (unpublished results).

Cyclophosphamide (Cytoxan). For the treatment of human advanced Hodgkin's disease, combination therapy with anti-cancer agents including vincristine, nitrogen mustard/cyclophosphamide, and procarbazine may be performed in a cyclic manner. ${ }^{10)}$ One report indicated that the agent may induce rheumatoid arthritis, urinary bladder tumors, and acute nonlymphatic leukemias in treated patients. ${ }^{11)}$

In nonhuman primates, initial dosing with cyclophosphamide by po administration was started in 1980 with 20 monkeys (10 rhesus, 9 cynomolgus and 1 hybrid monkeys) at a dose of $6.0 \mathrm{mg} / \mathrm{kg}$ 5 days a week. This was discontinued after 11 years of dosing, when fifteen of the animals were surviving, among which one rhesus monkey was found to have a small transitional cell carcinoma of the urinary bladder, and one rhesus and one hybrid monkey demonstrated myocardial degeneration and fibrosis. ${ }^{5)}$

Melphalan (L-PAM). Dosing of melphalan to 20 nonhuman primates was started in 1975 and terminated in 1991 after approximately 16 years. This agent was given by po route at $0.1 \mathrm{mg} / \mathrm{kg}, 5$ times a week, and the average cumulative dose was $2.17 \mathrm{~g}$.

Interestingly, the incidence of endometriosis was found to be higher than in any of the other experimental groups in this study. At autopsy 5 cynomolgus monkeys were diagnosed as having malignant tumors, one being found to have an endometrial adenocarcinoma, and two demonstrating poorly differentiated sarcomas in the perineal and perivaginal area of unknown origin, one metastasizing to the lung. In addition, a prostate carcinoma (Fig. 1) and a squamous cell carcinoma of the palate were diagnosed. Six animals were found to have benign tumors (four with leiomyomas of the uterus, one with a lung adenoma, and one with an eccrine cylindroma of the scalp) (unpub-

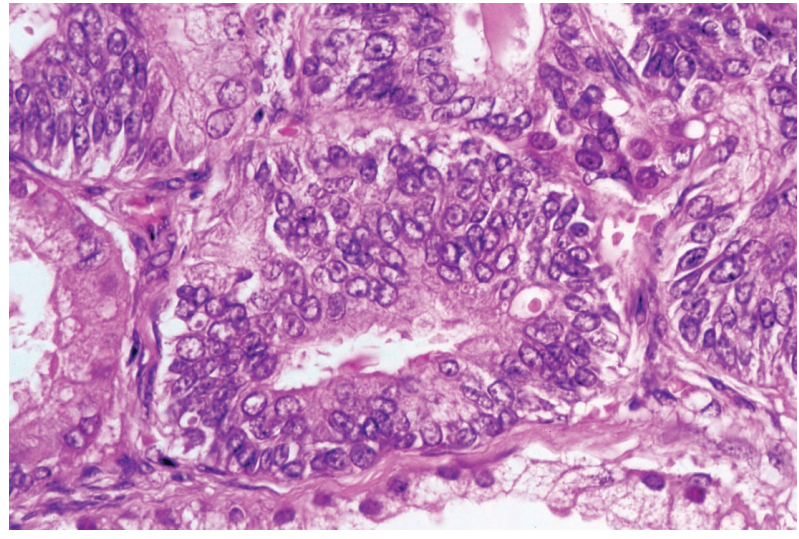

Fig. 1. Adenocarcinoma of the prostate, demonstrating well differentiated glandular proliferation of neoplastic cells. (Cynomolgus male, 296 months old, L-PAM $100 \mathrm{mg} / \mathrm{kg}$ group). $\times 245$.

lished data).

Procarbazine (MIH). Administration of procarbazine was initiated in 1963 and terminated in 1985. This agent was given to 53 newborn animals by the ip, sc, and/or po routes. Forty-nine animals survived for 6 months or longer after the initial dose. Malignant tumors were found in 17 animals, and the average cumulative dose in these tumorbearing animals was $73.7 \mathrm{~g}$. The tumors included 8 cases of acute nonlymphatic leukemia, 2 renal hemangiosarcomas, 3 osteosarcomas, 1 lymphocytic lymphoma, 1 osteocytoma, and 1 colon carcinoma. One animal had two primary tumors, in the pancreas and the renal pelvis. The most common cause of death in the remaining animals in this group was bone marrow atrophy. Another interesting finding was depression of spermatogenesis (Sertoli-cell-only syndrome), which was found in 18 of 29 male animals. ${ }^{5), 12)}$

$N$-Methyl-N-nitrosourea (MNU). MNU exerts direct carcinogenic effects and does not require enzymatic activation. It was administered at a po dose of $10 \mathrm{mg} / \mathrm{kg}$, incorporated into vitamin sandwiches, for 10 years to a total of $43^{13)}$ or $44^{4), 5)}$ nonhuman primates. Twenty six animals died without tumors. Malignant tumors were observed in all the remaining 18 animals, which received an average cumulative dose of $140.4 \mathrm{~g}$ and had an average latent period of 146.5 months (range, 62264 months). ${ }^{5)}$ Invasive squamous cell carcinomas in the lower third of the esophagus were found in 15 animals; 7 of these animals had a single primary 
tumor, while the remaining 8 had multiple tumors. In addition, squamous cell carcinomas were found in the oral cavity, pharynx, larynx, and stomach. One animal (cynomolgus monkey) had 3 primary tumors a squamous cell carcinoma of the esophagus, an adenocarcinoma of the stomach, and a rhabdomyoblastoma of the heart. All of the animals having squamous cell carcinomas of the esophagus also had severe dysplasia of non-tumorous areas of the esophageal mucosa. ${ }^{4,5), 13)}$

Artificial sweeteners. Saccharin. In the early 1970's, saccharin was reported to induce bladder tumors in rats. ${ }^{14)}$ However, the mechanism of its carcinogenicity was shown to be specific to rats. ${ }^{15)}$ Thus saccharin was removed from the US NTP List of Carcinogens in Dec., 2000. Epidemiological studies have shown no evidence of increased urothelial proliferation associated with ingestion of sodium saccharin in humans.

For the purpose of clarifying whether saccharin might be carcinogenic to nonhuman primates, a long-term (24 years) feeding study was started in 1970. Twenty animals of three species, cynomolgus, rhesus, African green and hybrid monkeys, 1-10 days of age, were treated with sodium saccharin mixed in the diet $(25 \mathrm{mg} / \mathrm{kg}$ body weight daily) 5 days a week; this dose corresponds to a daily intake of 5 cans of diet soda by a $70 \mathrm{~kg}$ person. Dosing started 24 hours after birth and continued for up to 24 years. Sixteen animals served as controls. During their last 2 years of life, urine was collected from selected saccharin-treated and control animals and evaluated for various urinary chemicals and for the presence of calculi, microcrystalluria, and precipitates. Sodium saccharin treatment had no effect on the urine or urothelium in any of these animals, and there was no evidence of formation of crystalline material in the urine. No tumors were detected at autopsy of the saccharin-treated animals (Table 3 ). Since the dose of sodium saccharin administered to these animals was 10 times the daily intake for humans by law, the results provided compelling evidence of no carcinogenic hazard risk for the primate urinary tract. ${ }^{16)}$

Cyclamate and cyclohexylamine. In 1970, a report of increase in the incidence of bladder tumors in rats dosed with a mixture of cyclamate and saccharin (10:1) led to a ban on cyclamate as an artificial dietary sweetener in the UK and the USA. ${ }^{17)}$ The safety issue was decided based on cyclamate data from rodent studies, including possible carcinogenicity, cardiovascular effects, and testicular toxicity. Cyclamate is metabolized by the bacterial flora of the gastrointestinal tract and the extent of conversion to cyclohexylamine is especially significant. ${ }^{18)}$ This metabolite is more toxic than the parent compound and has been shown to produce testicular atrophy in both rats and dogs. ${ }^{19)}$

Commencing in 1970, cyclamate was administered to cynomolgus, rhesus, and African green monkeys in the diet at $100 \mathrm{mg} / \mathrm{kg}$ or $500 \mathrm{mg} / \mathrm{kg}$, 5 times per week from birth for up to 24 years. Twenty-one animals were used in this experiment. Seven died during the study without any tumors, and the survivors were in good health until the study was terminated in 1994 . The remaining 8 animals in the $100 \mathrm{mg} / \mathrm{kg}$ group and 6 in the $500 \mathrm{mg} / \mathrm{kg}$ were euthanized and necropsied. Kyphosis of the spine was observed in 3 monkeys. Malignant tumors were diagnosed in three animals at age 24 ; one was a well-differentiated prostate carcinoma in the $100 \mathrm{mg} / \mathrm{kg}$ group and the other two were a metastatic colon adenocarcinoma and a hepatocellular carcinoma with lung metastasis which occurred in the $500 \mathrm{mg} / \mathrm{kg}$ group (Table 3 ). Benign tumors, i.e., an adenoma of the thyroid gland and a leiomyoma of the uterus, were found in two females at autopsy. Testicular atrophy with evidence of decreased spermatogenesis was observed in 5 of 7 males in the $500 \mathrm{mg} / \mathrm{kg}$ cyclamate group, and in 3 of 4 males in the $100 \mathrm{mg} / \mathrm{kg}$ group. Terminal measurement of cyclohexylamine concentrations showed that three of the cyclamate monkeys were high metabolic converters with plasma levels comparable to that produce testicular atrophy in rats. However, only one of the three high converters showed evidence of testicular atrophy. ${ }^{20)}$

The findings of this study suggest that lifetime exposure to high doses of cyclamate accelerates the process of age-related testicular atrophy in three species of animals. Although the tumor incidence in cyclamate monkeys was higher than the overall spontaneous tumor rate in the breeders and normal controls in the 35 years history of this monkey colony, the three cases of different types of malignant tumor in old animals are inconclusive regarding the carcinogenic potential of cyclamate. 
Table 3. Summary of malignant tumor data for monkeys treated with saccharin, cyclamate, DDT and heterocyclic amines

\begin{tabular}{lccccc}
\hline Agent & $\begin{array}{c}\text { No. of } \\
\left.\text { monkeys }^{\mathrm{a}}\right)\end{array}$ & Route & $\begin{array}{c}\text { Daily dose } \\
(\mathrm{mg} / \mathrm{kg})\end{array}$ & $\begin{array}{c}\text { No. dead with } \\
\text { malignant tumor }\end{array}$ & Carcinogenicity \\
\hline Saccharin & 20 & po & 25 & 0 & no \\
Cyclamate & 10 & po & 100 & 1 & no \\
Cyclamate & 11 & po & 500 & 2 & no \\
DDT & 25 & po & 20 & 2 & not \\
1Q & 20 & ng & 10 & 9 & conclusive \\
1Q & 20 & ng & 20 & 17 & yes \\
MeIQx & 10 & ng & 20 & 0 & no \\
MeIQx & 10 & ng & 10 & 0 & no \\
PhIP & 10 & ng & 20 & 0 & no \\
PhIP & 10 & ng & 10 & 0 & no \\
\hline
\end{tabular}

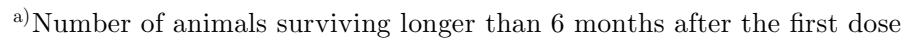

Cooked foods mutagens and carcinogens.

Heterocyclic amines (HCAs). In 1986, highly mutagenic HCAs were isolated from broiled, fried, and barbecued meat and fish. ${ }^{21}$ These HCAs were subsequently shown to be carcinogenic in various organs in rodents following oral administration. ${ }^{22)}$ Three HCAs, i.e., 2-amino-3-methylimidazo[4,5-f] quinoline (IQ), 2-amino-3,8-dimethylimidazo(4,5f)quinoxaline (MeIQx), and 2-amino-1-methyl-6phenylimidazo(4,5-b)pyridine (PhIP), were evaluated in nonhuman primates by ng intubation at doses of 10 and $20 \mathrm{mg} / \mathrm{kg}, 5$ days a week. Of the three HCAs, IQ was found to be a potent hepatic carcinogen in cynomolgus monkeys. Liver tumors were thus found in 9 of 20 animals (45\%) in the $10 \mathrm{mg} / \mathrm{kg}$ group and in 17 of 20 animals $(85 \%)$ in the $20 \mathrm{mg} / \mathrm{kg}$ group. The average cumulative doses were $38.2 \mathrm{~g}$ and $43.9 \mathrm{~g}$, respectively, and average latent periods were 59.1 and 44.8 months. Most of the liver tumors were diagnosed as hepatocellular carcinomas (Fig. 2). The extent of tumor involvement ranged from a single nodule to almost complete replacement of the liver with nodules. Hepatocellular carcinomas with metastases to the lung and omentum were found in 6 tumor-bearing animals. ${ }^{23)}$

MeIQx is carcinogenic towards rodents, inducing liver and lung tumors, lymphomas, and leukemia in CDF1 mice, and liver, Zymbal gland, and skin tumors in F344 rats. ${ }^{21)}$ In a study which began in 1988,20 cynomolgus monkeys received this agent at doses of 10 or $20 \mathrm{mg} / \mathrm{kg}$, by nasogastric intubation as with IQ, 5 times a week for a period of 84

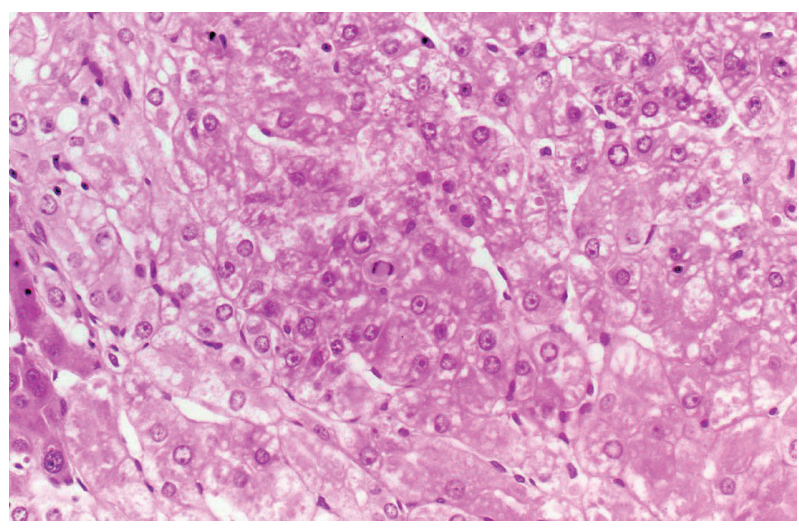

Fig. 2. Trabecular hepatocellular carcinoma, characterized by channels lined with discontinuous layers of endothelial cells (Cynomolgus male, 61 months old, IQ $100 \mathrm{mg} / \mathrm{kg}$ group). $\times 185$.

months, and were autopsied 8 months thereafter. However, no neoplastic or preneoplastic lesions were observed. ${ }^{24)}$

The specific mutagenic activity of PhIP in tests using Salmonella typhimurium TA98 is much lower than that of IQ and MeIQx, but it is present at up to 10 -fold higher levels in cooked beef. PhIP has been reported to show carcinogenicity in various organs, including breast, colon and prostate cancers in rodents. ${ }^{21)}$ Dosing of cynomolgus monkeys with $\mathrm{PhIP}$ by nasogastric intubation was started in 1990, groups of 10 monkeys received PhIP at levels of 10 and $20 \mathrm{mg} / \mathrm{kg}, 5$ days a week. At the end of the observation period at 82 months, no macroscopic lesions in the intestines or treatment-related histo- 
pathological findings in other organs were observed in these animals (Tsuda, H. personal communication).

Naturally occurring compound and pesticide. Aflatoxin $B_{1}\left(A F B_{1}\right)$. Carcinogenicity studies of $\mathrm{AFB}_{1}$ in cynomolgus and rhesus monkeys were commenced in 1966. Oral dosing was started at 2 weeks of age. During the first month, $\mathrm{AFB}_{1}$ was given two to three times weekly at $0.05 \mathrm{mg} / \mathrm{kg}$. The dose was then raised steadily up to $0.8 \mathrm{mg} / \mathrm{kg}$ over the next 6 months, using the same dosing frequency. A second group of newborn animals received $\mathrm{AFB}_{1}$ ip injection, starting at $0.2 \mathrm{mg} / \mathrm{kg}$ once weekly and reaching $0.25 \mathrm{mg} / \mathrm{kg}$ at 2 months of age. The third group was dosed by both po and ip routes. Twentyeight of the animals in the first group survived for more than 6 months, 18 of which developed malignant tumors. In the second and third groups, 5 animals survived for more than 6 months in each group, all of which developed malignant tumors. Dosing of $\mathrm{AFB}_{1}$ was continued until the end of the observation period of 18 years. A third of the animals with malignancies had more than one primary tumor. A total of 29 tumors $^{4), 5)}$ were found in 23 animals, including 10 bile duct carcinomas, ${ }^{5)} 3$ hepatocellular carcinomas, ${ }^{5)} 3$ adenocarcinomas of the pancreas, ${ }^{5)} 7$ hemangiosarcomas of the liver, ${ }^{5)}$ 3 osteosarcomas, ${ }^{5}{ }^{2} 2$ transitional cell carcinomas of the urinary bladder, ${ }^{5)}$ and 1 fibrosarcoma in the pelvic area.

The average cumulative dose for the tumorbearing animals was $885 \mathrm{mg}$. The observation periods were $48-74^{25)}$ or $48-210^{5)}$ months. The tumor incidence was considerably higher in females than in males. Among the 15 animals without tumors, 6 died as a result of toxic hepatitis, 4 developed cirrhosis, and 3 had hyperplastic nodules in the liver at the time of death. ${ }^{5), 25)}$

DDT. DDT has been used extensively throughout the world for agricultural pesticide and, recently, vector control of malaria. DDT is known to induce liver tumors in mice, rats and hamsters. ${ }^{26), 27)}$ DDT treatment was begun to a group of 15 nonhuman primates in 1969 and to another group of 10 in 1975 (Table 2). ${ }^{5)}$ The dosage in both cases was $20 \mathrm{mg} / \mathrm{kg}$ by po route 5 times per week for a period of 130 months. At the end of the observation period (16-22 years), 15 animals were alive and in good health. Of the 10 animals that died, one developed a hepatocellular carcinoma after an observation period of almost 20 years and a total dose of $292 \mathrm{~g}$ and one had a carcinoma of the prostate (Table 3). Some animals showed severe tremors and convulsions immediately prior to death. One animal died as a result of toxic hepatitis 4.5 years after the first dose of DDT, and two developed diabetes mellitus after 14 and 17 years, respectively. One animal was diagnosed with a Sertoli-cell-only syndrome of the testis. ${ }^{12)}$ The results of the long-term DDT administration study in cynomolgus and rhesus monkeys emphasized the neurotoxic effects of DDT, although the findings also suggested hepatotoxicity. The two cases of different types of malignant tumors occurring in aged animals do not allow an unequivocal conclusion with respect to carcinogenetic effects of DDT in nonhuman primates. ${ }^{5), 28)}$

N-nitroso compounds. Dosing of monkeys with DENA, DMNA, DPNA, MNNG and PIP, was begun in 1962. With the exception of DMNA and MNNG, all of these compounds were shown to be unequivocal hepatocarcinogens in rats, as shown in Table $4 .^{5)}$

$D E N A$. DENA was the most potent and consistent liver carcinogen of all the compounds tested in the monkey colony, with an incidence of hepatic carcinomas of almost $100 \%$ within 2 years. DENA was given by po and ip routes, but the latter resulted in the shorter latent period (minimum of 6 months). DENA was used as a model hepatocarcinogen to study the relationship between cumulative dose and latent period for tumor formation and the dose-dependence. Histologically, toxic hepatitis, cirrhosis and adenomatous hyperplasia were observed in animals that survived longer than 6 months. Liver tumors induction showed a linear dose-dependence. ${ }^{5), 29)}$

$M N N G$. MNNG was incorporated into gelatin and inserted into the colons of three monkeys. One of the 3 animals developed an adenocarcinoma of the sigmoid-rectal region. In another experiment, 20 animals were dosed with MNNG by the po route at $4 \mathrm{mg} / \mathrm{kg}$, and the average cumulative dose was $34.8 \mathrm{~g}$ with an average observation period of 206 months (71-238 months). In this study, no malignant tumors were found and only one case of liver adenoma was noted in the longest surviving animal. Summaries of the results for DMNA, DPNA and PIP have been described in earlier publications. ${ }^{4), 5)}$ The data overall are summarized in Table 4 . 
Table 4. Data for malignant tumors in monkeys treated with N-nitroso compounds

\begin{tabular}{|c|c|c|c|c|c|c|c|}
\hline \multirow[b]{2}{*}{ Agent } & \multirow{2}{*}{$\begin{array}{l}\text { No. } \\
\text { Monkeys }\end{array}$} & \multirow[b]{2}{*}{ Route } & \multirow{2}{*}{$\begin{array}{l}\text { Daily Dose } \\
(\mathrm{mg} / \mathrm{kg})\end{array}$} & \multicolumn{2}{|c|}{ Average } & \multirow{2}{*}{$\begin{array}{c}\text { No. dead with } \\
\text { malignant } \\
\text { tumor }\end{array}$} & \multirow{2}{*}{$\begin{array}{l}\text { Carcino- } \\
\text { genicity }\end{array}$} \\
\hline & & & & $\begin{array}{l}\text { Cumulative dose } \\
(\mathrm{g})\end{array}$ & $\begin{array}{c}\text { Observation period } \\
\text { (months) }\end{array}$ & & \\
\hline DENA & 40 & po & $10 \rightarrow 40$ & 2.18 & & 31 & yes \\
\hline DENA & 128 & ip & $10 \rightarrow 40$ & & & 112 & yes \\
\hline DPNA & 6 & ip & 40 & 6.97 & 29 & 6 & yes \\
\hline PIP & 10 & ip & 40 & 26.69 & 141 & 6 & yes \\
\hline PIP & 12 & po & 400 & 51.47 & 87 & 11 & yes \\
\hline MNNG & 20 & po & 4 & 34.8 & 206 & 0 & no \\
\hline MNNG & 3 & $\operatorname{irec}^{\mathrm{a})}$ & 4 & $8.5^{\mathrm{b})}$ & 73 & 1 & $\begin{array}{c}\text { not } \\
\text { conclusive }\end{array}$ \\
\hline DMNA & 7 & ip & 7.25 & 7 & 54 & 0 & no \\
\hline
\end{tabular}

a) Intrarectal administration; b) Total dose of MNNG

Data, modified from Thorgeirsson et al.

Table 5. Data for malignant tumors in monkeys treated with classical rodent carcinogens

\begin{tabular}{|c|c|c|c|c|c|c|c|}
\hline \multirow{2}{*}{ Agent } & \multirow{2}{*}{$\begin{array}{l}\text { No. of } \\
\text { Monkeys }\end{array}$} & \multirow{2}{*}{ Route } & \multirow{2}{*}{$\begin{array}{l}\text { Daily Dose } \\
(\mathrm{mg} / \mathrm{kg})\end{array}$} & \multicolumn{2}{|c|}{ Average } & \multirow{2}{*}{$\begin{array}{c}\text { No. dead with } \\
\text { malignant } \\
\text { tumor }\end{array}$} & \multirow{2}{*}{$\begin{array}{l}\text { Carcino- } \\
\text { genicity }\end{array}$} \\
\hline & & & & $\begin{array}{c}\text { Cumulative dose } \\
(\mathrm{g})\end{array}$ & $\begin{array}{l}\text { Observation period } \\
\text { (months) }\end{array}$ & & \\
\hline $\begin{array}{l}\text { 4-dimethylamino- } \\
\text { azobenzene }\end{array}$ & 7 & po & 120 & 15.27 & 240 & 1 & no \\
\hline $\begin{array}{l}\text { 2-acetylamino- } \\
\text { fluorene }\end{array}$ & 13 & po & 120 & 139.9 & 240 & 1 & no \\
\hline $\begin{array}{l}2,7 \text {-bisacetyl- } \\
\text { aminofluorene }\end{array}$ & 14 & po & 100 & 97.8 & 202 & 1 & no \\
\hline 3-MC & 18 & po & 120 & $73^{\text {a) }}$ & 191 & 0 & no \\
\hline
\end{tabular}

a) Number of animals surviving longer than 6 months after the first dose

Classical rodent carcinogens. The classical rodent carcinogens investigated included 4-dimethylaminoazobenzene (butter yellow), 2-acetylaminofluorene (2-AAF), 2,7-bis-acetylaminofluorene (2,7-AAF), and 3-methylcholanthrene (3-MC). These compounds were the first chemicals to be evaluated in the monkey colony in 1961 and 1962. The animals were dosed by the po route for 5 years at levels comparable to those given to rodents. The daily doses, average cumulative doses, and observation periods and tumorgenicity are shown in Table 5. Only one animal had a malignant tumor in each treatment group. The tumors were a bronchioalveolar carcinoma in the butter yellow group, an adenocarcinoma of the nipple in the 2-AAF group and a medullary carcinoma of the mammary gland in the 2,7-AAF group. Thus the results preclude any conclusion concerning carcinogenicity in nonhuman primates. In the 3 -MC group, the average cumulative dose was $73.0 \mathrm{mg}$ and the average observation period was 191 months. No tumors were found. ${ }^{5}$ )

\section{Discussion}

Experimental data obtained from rodents have been extrapolated to infer carcinogenic risk to humans. ${ }^{1)}$ However, agents that are carcinogenic in man do not necessarily have similar effects in rodents and vice versa so that nonhuman primates are generally considered important animals for assessment of human carcinogenic risk (Table 6). The reason for the long-term program described here (initiated in 1961) was the lack of information on susceptibility of nonhuman primates to suspected human carcinogens and established rodent carcinogens. $^{2)}$

A number of widely used chemotherapeutic agents were previously reported to be carcinogenic in rodents. ${ }^{30)}$ Of the five chemotherapeutic agents that were evaluated in the present study, procar- 
Table 6. Tumorigenicity in humans, nonhuman primates and rodents

\begin{tabular}{|c|c|c|c|}
\hline Agents & $\begin{array}{l}\text { Human } \\
\text { (IARC Evaluation) }\end{array}$ & $\begin{array}{l}\text { Nonhuman } \\
\text { primates }\end{array}$ & Rodents \\
\hline $\begin{array}{l}\text { Doxorubicin } \\
\text { hydrochloride }\end{array}$ & Probably yes (2A) & not conclusive & yes \\
\hline Cyclophosphamide & yes $(1)$ & not conclusive & yes \\
\hline Merphalan & Possibly yes (2B) & not conclusive & yes \\
\hline Procarbazine & yes $(1)$ & yes & yes \\
\hline $\mathrm{MNU}$ & Probably yes (2A) & yes & yes \\
\hline Saccharin & no & no & yes \\
\hline Cyclamate & no & no & yes \\
\hline DDT & yes $(2 B)$ & not conclusive & yes \\
\hline IQ & Probably yes $(2 \mathrm{~A})$ & yes & yes \\
\hline MeIQx & Possibly yes (2B) & no & yes \\
\hline $\mathrm{PhIP}$ & Possibly yes (2B) & no & yes \\
\hline $\begin{array}{l}\text { 4-Dimethylamino- } \\
\text { azobenzene }\end{array}$ & Possibly yes (2B) & no & yes \\
\hline $\begin{array}{l}\text { 2-Acethylamino- } \\
\text { fluorene }\end{array}$ & not available & no & yes \\
\hline $\begin{array}{l}2,7 \text {-Bisacethylamino- } \\
\text { fluorene }\end{array}$ & not available & no & yes \\
\hline 3-MC & not available & no & yes \\
\hline
\end{tabular}

bazine (MIH) and MNU were shown to have carcinogenic potency. Thus acute non-lymphatic leukemia was found in 8 of 17 animals in the group treated with procarbazine, while squamous cell carcinomas of the esophagus were observed in 18 of 26 animals treated with MNU. ${ }^{13)}$ Clinically, procarbazine was used as a single antineoplastic agent for Hodgkin's disease prior to the introduction of the MOPP (mechlorethamine, oncovin, procarbazine and prednisone) regimen and is known to prolong survival in the patients. ${ }^{10)}$ Although an increased incidence of myelogenic leukemia was reported in procarbazine-treated individuals, ${ }^{31)}$ it was not possible to determine whether the drug was actually responsible for the secondary malignancies. The finding that almost half of the nonhuman primates treated with procarbazine developed leukemia, however, provided strong support for an etiological link in Hodgkin's disease patients.

MNU, in combination with cyclophosphamide, was used previously in the Soviet Union for treatment of Hodgkin's disease and undifferentiated carcinoma of the lung. ${ }^{32)}$ However, MNU was shown to induce squamous cell carcinomas of the upper gastrointestinal tract in more than one-third of the nonhuman primates. This suggests that MNU exerts direct carcinogenic effects in the upper gastrointestinal tract following oral administration. Since chronic inflammation was commonly observed in the esophagus causing increase in cell proliferation, one may suspect that it was a factor contributing to tumor development in the esophagus of the MNU-treated animals. ${ }^{5)}$ Other interesting findings in the MNU-treated animals included endometriosis in 7 of 24 females and one case of ovarian cyst in this group. The high incidence of endometriosis in the MNU group may be related to hormonal dysfunction in these animals.

Melphalan has been used as a chemotherapeutic agent, but was shown to be associated with an increased incidence of acute leukemias and multiple myelomas in patients. In the nonhuman primates studied, various benign and malignant tumors developed in the melphalan group, but none of them were leukemias. The high incidence of endometriosis associated with long-term melphalan treatment may suggest an endocrine effect. Since the etiology of endometriosis has not yet been clearly elucidated, the melphalan treated-animal may serve as an important experimental model for the human disease. ${ }^{33), 34)}$

Cyclophosphamide has been used for prolonged treatment of rheumatoid arthritis and malignancies and as an immunosuppressive agent. Treatment 
for long periods has been reported to result in the development of secondary malignancies, such as leukemias and bladder cancer. ${ }^{32), 35)}$ In the long-term study described here, cyclophosphamide was administered to nonhuman primates for 11 years but only one small transitional cell carcinoma of the urinary bladder was found. This can not constitute evidence of carcinogenic effects in humans. ${ }^{11)}$

The monkey data support epidemiological findings which failed to show an increased incidence of urinary tract tumors in humans following chronic saccharin consumption. Since urine analysis of saccharin-treated primates revealed a similar composition to that of human urine, contrasting with much higher protein concentrations in the urine of rats and mice, this may help explain the apparent difference in carcinogenic activity between primates and rodents. ${ }^{16)}$ Life-time feeding with sodium cyclamate to nonhuman primates did not affect the general health and there was no clear evidence of carcinogenicity. The testis is the most sensitive organ to the toxic effects of cyclohexylamine in rats, according to reports by the Scientific Committee for Food of the Commission of the European Communities. The metabolic status was calculated from cyclohexylamine levels in plasma and urine of the monkeys after 14 and 24 years of dosing, but differences were noted between the two time points in some of the animals. Focal germ cell aplasia (Sertoli-cell-only syndrome) was observed in two of eleven cyclamate-treated animals in the higher dose $(500 \mathrm{mg} / \mathrm{kg})$ group but none in the lower dose $(100 \mathrm{mg} / \mathrm{kg})$ or control groups. Because of the focality of these testicular lesions and fluctuations in the cyclamate metabolism in the animals with testicular abnormalities, the role of cyclohexylamine could not be established. ${ }^{19), 20)}$

Compounds listed as food contaminants, pesticides and $\mathrm{HCAs}$, like azodyes, $\mathrm{AFB}_{1}$, sterigmatocystin, and cycasin, have been reported previously to be carcinogenic, ${ }^{5)}$ most targeting the liver. However, only one malignant tumor was observed in each of the groups of monkeys treated with DDT, butter yellow, and 3-MC, despite long-term continuous exposure to these agents for 22 years. Far clearer results were obtained with one of the three HCAs tested. The HCAs IQ, MeIQx, and PhIP are found in fried, broiled, and grilled meat, and have been shown to be carcinogenic to various organs in rodents. Mutagenic activity in the Ames test was found to weaker for PhIP than for IQ and MeIQx. ${ }^{21), 22)}$ Only IQ proved to be an unequivocal hepatocarcinogen in nonhuman primates but not MeIQx. ${ }^{23), 24)}$

Humans and other primates show marked similarities in drug metabolism, but recent studies on metabolic activation of HCAs in cynomolgus monkeys have indicated species-related differences in cytochrome P-450-mediated metabolic activation of HCAs. ${ }^{36)-39)}$ For example, low metabolic ativation of MeIQx by CYP3A and CYP2C, under a low constitutive level of CYP1A, can explain the low hepatocarcinogenic effects of MeIQx in cynomolgus monkeys. ${ }^{24)}$ In contrast, the human and rat which poorly express liver CYP1A1 are known to constitutively induce liver CYP1A2. ${ }^{40)}$ Furthermore, such species specificity of susceptibility to HCA carcinogenesis may be related to differences in phase II activation. ${ }^{41)}$ In humans, the hepatic microsomal fraction activates IQ as well as MeIQx and PhIP, and intake of fried meat was shown to increase CYP1A2 activity in healthy volunteers. ${ }^{42)}$

Thus, the 34 years chemical carcinogenesis program using nonhuman primates, beginning in 1961, has generated a wealth of valuable knowledge concerning potential human carcinogens. One goal was to determine whether rodent carcinogens are also carcinogenic in nonhuman primates much closer to man in terms of the evolutionary tree. Among 15 selected rodent carcinogens, procarbazine, MNU and IQ were carcinogenic in both rodents and nonhuman primates (Table 6 ). Together with the data for DENA carcinogenicity, these point to shared susceptibility to some, but not all, agents. Furthermore, the recent experiments on carcinogenic effects of antineoplastic agents and HCAs are of particular interest to human risk assessment. The lack of carcinogenicity of saccharin and cyclamate following investigation for 24 years is of major significance in these series of experiments.

\section{Acknowledgments}

We thank our colleagues involved in the studies on nonhuman primates described in this review. Our appreciation is also due to Drs. O. Makabe and S. Hoshiko, and Ms. K. Yasufuku, Pharmaceutical Research Department, Meiji Seika Kaisha, Ltd., Yokohama, for their interest and assistance. 


\section{References}

1) Iatropoulos, M.J. (1992) Accelerated rodent bioassay predictive of chemical carcinogenesis. Exp. Toxicol. Pathol. 44, 481-487.

2) Gold, L.S., Slone, T.H., Manley, N.B. and Bernstein, L. (1991) Target organs in chronic bioassays of 533 chemical carcinogens. Environ Health Perspect. 93, 233-246.

3) Vainio, H. and Wilbourn, J. (1993) Cancer etiology: agents causally associated with human cancer. Pharmacol. Toxicol. 72 Suppl. 1, 4-11.

4) Dalgard, D.W. (1994-1997) Introduction, Biological Markers, and Therapy of Tumors in Primates. Final Report of Contract No. NO1-CP40510, The National Cancer Institute, Bethesda, MD, USA, Laboratory Project Identification: CHV Study No. 421-166, 1-177.

5) Thorgeirsson, U.P., Dalgard, D.W., Reeves, J. and Adamson, R.H. (1994) Tumor incidence in a chemical carcinogenesis study of nonhuman primates. Regul. Toxicol. Pharmacol. 19, 130 151.

6) IARC (2004) Some drinking-water disinfectants and contaminants, including arsenic. IARC Monogr. Eval. Carcinog. Risks Hum. 84, 41-267.

7) Takayama, S., Makita, T. and Thorgeirsson, U.P. (1999) Color Atlas of Nonhuman Primate Histology. Japan Scientific Society Press, Tokyo, S. Karger AG, Basel.

8) Takayama, S., Fukushima, S. and Thorgeirsson, U.P. (2000) Atlas of Spontaneous Tumors in Nonhuman Primates. Japan Scientific Society Press, Tokyo, S. Karger AG, Basel.

9) Lindower, P.D. and Skorton, D.J. (1992) High-dose Cancer Therapy. Williams and Wilkins, Baltimore, pp. 507-517.

10) Devita, V.T. Jr., Serpick, A.A. and Carbone, P.P. (1970) Combination chemotherapy in the treatment of advanced Hodgkin's disease. Ann. Intern. Med. 73, 881-895.

11) IARC (1981) Some antineoplastic and immunosuppressive agents. IARC Monogr. Eval. Carcinog. Risks Hum. 26, 165-202.

12) Sieber, S.M., Correa, P., Dalgard, D.W. and Adamson, R.H. (1978) Carcinogenic and other adverse effects of procarbazine in nonhuman primates. Cancer Res. 38, 2125-2134.

13) Adamson, R.H., Krollkowski, F.J., Correa, P., Sieber, S.M. and Dalgard, D.W. (1977) Carcinogenecity of 1-methyl-1-nitrosourea in nonhuman primates. J. Natl. Cancer Inst. 59, 415-422.

14) IARC (1999) Some chemicals that cause tumors of the kidney or urinary bladder in rodents and some other substances. IARC Monogr. Eval. Carcinog. Risks Hum. 73, 517-624.

15) IARC (1999) Working Group Consensus Report. IARC Scientific Publication 147, 1-32.

16) Takayama, S., Sieber, S.M., Adamson, R.H., Thorgeirsson, U.P., Dalgard, D.W., Arnold, L.L., Cano, M., Eklund, S. and Cohen, S.M.
(1998) Long-term feeding of sodium saccharin to nonhuman primates: implications for urinary tract cancer. J. Natl. Cancer Inst. 90, 19-25.

17) Price, J.M., Biava, C.G., Oser, B.L., Vogin, E.E., Steinfeld, J. and Ley, H.L. (1970) Bladder tumors in rats fed cyclohexylamine or high doses of a mixture of cyclamate and saccharin. Science 167, $1131-1132$.

18) Renwick, A.G. (1986) The metabolism of intense sweeteners. Xenobiotica 16, 1057-1071.

19) Bopp, B.A., Sonders, R.C. and Kesterson, J.W. (1986) Toxicological aspects of cyclamate and cyclohexylamine. Crit. Rev. Toxicol. 16, 213306.

20) Takayama, S., Renwick, A.G., Johansson, S.L., Thorgeirsson, U.P., Tsutsumi, M., Dalgard, D.W. and Sieber, S.M. (2000) Long-term toxicity and carcinogenicity study of cyclamate in nonhuman primates. Toxicol. Sci. 53, 33-39.

21) Sugimura, T. (1995) Heterocyclic Amines in Cooked Foods: Possible Human Carcinogens. Princeton Scientific Pub. Co. Inc., Princeton, NJ, pp. 214-231.

22) Sugimura, T. (1986) Studies on environmental chemical carcinogenesis in Japan. Science 233, $312-318$.

23) Adamson, R.H., Thorgeirsson, U.P., Snyderwine, E.G., Thorgeirsson, S.S., Reeves, J., Dalgard, D.W., Takayama, S. and Sugimura, T. (1990) Carcinogenicity of 2-amino-3-methylimidazo[4,5-f]quinoline in nonhuman primates: induction of tumors in three macaques. Jpn. J. Cancer Res. $\mathbf{8 1}, 10-14$

24) Ogawa, K., Tsuda, H., Shirai, T., Ogiso, T., Wakabayashi, K., Dalgard, D.W., Thorgeirsson, U.P., Thorgeirsson, S.S., Adamson, R.H. and Sugimura, T. (1999) Lack of carcinogenicity of 2-amino-3,8-dimethylimidazo[4,5-f] quinoxaline (MeIQx) in cynomolgus monkeys. Jpn. J. Cancer Res. 90, 622-628.

25) Adamson, R.H., Correa, P., Sieber, S.M., Mcintire, K.R. and Dalgard, D.W. (1976) Carcinogenicity of aflatoxin B1 in rhesus monkeys: two additional cases of primary liver cancer. J. Natl. Cancer Inst. 57, 67-78.

26) Tomatis, L., Turusov, V., Day, N. and Charles, R.T. (1972) The effect of long-term exposure to DDT on CF-1 mice. Int. J. Cancer 10, 489-506.

27) IARC (1991) Occupational exposures in insecticide application and some pesticides. IARC Working Group on the Evaluation of Carcinogenic Risks to Humans. Lyon, IARC Monogr. Eval. Carcinog. Risks Hum. 53, 179-249.

28) Takayama, S., Sieber, S.M., Dalgard, D.W., Thorgeirsson, U.P. and Adamson, R.H. (1999) Effects of long-term oral administration of DDT on nonhuman primates. J. Cancer Res. Clin. Oncol. 125, 219-225.

29) Lapis, K., Zalatnai, A., Timar, F. and Thorgeirsson, U.P. (1995) Quantitative evaluation of lysozyme- and CD68-positive Kupffer cells in diethylnitrosamine-induced hepatocellular 
carcinomas in monkeys. Carcinogenesis 16, 30833085 .

30) Weisburger, E.K. (1977) Bioassay program for carcinogenic hazards of cancer chemotherapeutic agents. Cancer 40, 1935-1949.

31) Adamson, R.H. and Sieber, S.M. (1983) Origins of Human Cancer. Cold Spring Harbor Laboratory, Cold Spring Harbor, NY, 429-443.

32) Kolaric, K. (1977) Combination chemotherapy with 1-methyl-1-nitrosourea (MNU) and cyclophosphamide in solid tumors. Z. Krebsforsh. Klin. Onkol. 89, 311-319.

33) Karchmer, R.K., Amare, M., Larsen, W.E., Mallouk, A.G. and Caldwell, G.G. (1974) Alkylating agents as leukemogens in multiple myeloma. Cancer 33, 1103-1107.

34) Kyle, R.A., Pierre, R.V. and Bayrd, E.D. (1974) Primary amyloidosis and acute leukemia associated with melphalan therapy. Blood 44, 333-337.

35) Schmahl, D., Habs, M., Lorenz, M. and Wagner, I. (1982) Occurrence of second tumors in man after anticancer drug treatment. Cancer Treat. Rev. 9, 167-194.

36) Smith, R.L. and Williams, R.T. (1974) Comparative metabolism of drugs in man and monkeys. J. Med. Primatol. 3, 138-152.

37) Snyderwine, E.G., Schut, H.A., Adamson, R.H., Thorgeirsson, U.P. and Thorgeirsson, S.S. (1992) Metabolic activation and genotoxicity of heterocyclic arylamines. Cancer Res. 52, 2099s2102s.
38) Snyderwine, E.G., Turesky, R.J., Buonarati, M.H., Turlehaub, K.W. and Adamson, R.H. (1995) Heterocyclic Amines in Cooked Foods: Possible Human Carcinogens. Princeton Scientific Pub. Co. Inc., Princeton, NJ, pp. 60-69.

39) Snyderwine, E.G., Turesky, R.J., Turteltaub, K.W., Davis, C.D., Sadrieh, N., Schut, H.A., Nagao, M., Sugimura, T., Thorgeirsson, U.P., Adamson, R.H. and Thorgeirsson, S.S. (1997) Metabolism of food-derived heterocyclic amines in nonhuman primates. Mutat. Res. 376, 203210.

40) Sadrieh, N. and Snyderwine, E.G. (1995) Cytochromes P450 in cynomolgus monkeys mutagenically activate 2-amino-3-methylimidazo[4,5-f]quinoline (IQ) but not 2-amino-3,8-dimethylimidazo[4,5-f] quinoxaline (MeIQx). Carcinogenesis 16, $1549-1555$.

41) Davis, C.D., Schut, H.A. and Snyderwine, E.G. (1993) Enzymatic phase II activation of the N-hydroxylamines of IQ, MeIQx and PhIP by various organs of monkeys and rats. Carcinogenesis 14, 2091-2096.

42) Edwards, R.J., Murray, B.P., Murray, S., Schulz, T., Neubert, D., Gant, T.W., Thorgeirsson, S.S., Boobis, A.R. and Davies, D.S. (1994) Contribution of CYP1A1 and CYP1A2 to the activation of heterocyclic amines in monkeys and human. Carcinogenesis 15, 829-836.

(Received Mar. 18, 2008; accepted Apr. 28, 2008) 


\section{Profile}

Shozo Takayama was born in 1928. He graduated from the Medical School of Tokyo Medical and Dental University in 1950 and received a Doctorate in Medical Science from the Department of Pathology, Tokyo Medical Dental University, in 1957.

After a 2-year training course in general pathology, he accepted a position as a research assistant at the Department of Pathology, Cancer Institute, Japanese Foundation for Cancer Research. In 1957, he was awarded a Fulbright scholarship and worked at the Sloan-Kettering Institute, NY, where he successfully performed heterotransplantation of human cancer in mice. In 1958, he returned to the Department of Pathology, Cancer Institute, Japanese Foundation for Cancer

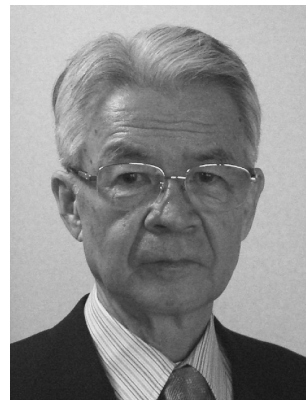
Research where he worked for 32 years. In the earlier phase of his studies at the Cancer Institute, he was involved in human surgical pathology, including pathological autopsy, and then moved from human to experimental pathology. Examples of his work include demonstration of carcinogenic activity of AF-2 in mice and rats, nitropyrenes in hamsters, and cigarette condensates in mice. He also established fish experimental models, such as erythrophroma in goldfish and induction of hepatic carcinoma in Medaka.

By collaboration with Takashi Sugimura's group at the National Cancer Center, Research Institute, his studies shifted to experiments regarding the carcinogenicity of various heterocyclic amines. He first demonstrated carcinogenic activity of Glu-P1, Glu-P2, IQ ane MeIQ, and PhiP in rodents. Also notable was a collaborative study of long-term carcinogenesis in nonhuman primates. From 1993 to 1997, he worked as a Senior Scientist and a Visiting Scientist at the National Cancer Institute, NIH, Bethesda, MD, USA under Richard H. Adamson and Unnur P. Thorgeirsson, where he was involved for over 32 years in histopathological studies of nonhuman primates given various environmental carcinogens.

He is now a Visiting Professor at Showa University, School of Medicine, Tokyo, Japan.

Takayama has published more than 350 papers, including two color atlases of nonhuman primates.

$\mathrm{He}$ is an honorary member of the Japanese Cancer Association, and the Japanese Pathological Society. He was awarded the Princess Takamatsu Cancer Research Fund Prize in 1980 and the Prince Hitachi Prize for Comparative Oncology in 1999. 